\title{
Associations between cruciferous vegetable intake and selected biomarkers among women scheduled for breast biopsies
}

\author{
Zhenzhen Zhang ${ }^{1, *}$, Lauren L Atwell ${ }^{2}$, Paige E Farris ${ }^{1}$, Emily Ho ${ }^{3,4}$ and Jackilen Shannon ${ }^{1}$ \\ 'School of Public Health, Oregon Health \& Science University, 3181 SW Sam Jackson Park Road, MC: GH153, \\ Portland, OR 97239, USA: ${ }^{2}$ School of Biological and Population Health Sciences, Oregon State University, Corvallis, \\ OR, USA: ${ }^{3}$ Linus Pauling Institute, Oregon State University, Corvallis, OR, USA: ${ }^{4}$ Moore Family Center for Whole \\ Grain Foods, Nutrition and Preventive Health, Oregon State University, Corvallis, OR, USA
}

Submitted 9 March 2015: Final revision received 16 June 2015: Accepted 14 July 2015: First published online 2 September 2015

\begin{abstract}
Objective: To examine the relationship between dietary cruciferous vegetable intake and selected tumour biomarkers for histone acetylation (H3K9ac, H3K18ac, HDAC3 and HDAC6), proliferation (Ki-67) and cell-cycle regulation (p21) from breast tissue.

Design: The study used baseline data of women recruited to participate in a clinical trial of sulforaphane supplement. Dietary cruciferous vegetable intake was collected through a validated Arizona Cruciferous Vegetable Intake Questionnaire. Breast tissue was obtained from biopsy samples. Spearman correlations were calculated between intake of specific cruciferous vegetables and biomarkers. Tissue biomarkers were $\log _{2}$-transformed to obtain approximate normality. Linear regression analyses were conducted to examine associations between cruciferous vegetable intake and biomarkers adjusting for age and use of non-steroidal anti-inflammatory drugs. False discovery rate (FDR) was used to account for multiple comparisons.

Setting: Clinical trial baseline.

Subjects: Fifty-four women who had abnormal mammogram findings and were scheduled for breast biopsy.

Results: Mean intake of total cruciferous vegetables from all food sources was 81.7 $(\mathrm{sD} 57.3) \mathrm{g} / \mathrm{d}$. Mean urinary total sulforaphane metabolites was 0.08 (SD 0.07) $\mu \mathrm{m} / \mathrm{mm}$ creatinine. Total cruciferous vegetable intake was inversely associated with Ki-67 protein expression in breast ductal carcinoma in situ (DCIS) tissue $(\beta=-0.004$; $\mathrm{SE}=0 \cdot 001 ; \mathrm{FDR} q$ value $=0.03)$, but not in benign or invasive ductal carcinoma (IDC) tissue. No association was found for other biomarkers measured (HDAC3, HDAC6, H3K9, H3K18 and p21) in all tissues examined (benign, DCIS and IDC).

Conclusions: The present study sought to provide additional evidence for the potential role of sulforaphane in histone acetylation and cell proliferation. Here, we report that total cruciferous vegetable intake is associated with decreased cell proliferation in breast DCIS tissue.
\end{abstract}

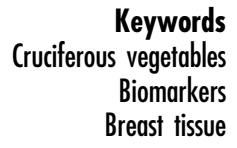

Breast cancer is the most prevalent cancer and the most common cause of death from cancer in women in the $\mathrm{USA}^{(1)}$. In 2013, approximately $21 \%$ of newly diagnosed breast cancer cases were in situ breast cancer with $85 \%$ of them as ductal carcinoma in situ (DCIS) ${ }^{(2)}$. DCIS starts with abnormal breast changes in the ductal cells and more than one-third of cases will develop into invasive cancer ${ }^{(2)}$. The progression from normal tissue to DCIS and to invasive cancer depends on many risk factors. Beyond conventional surgical treatment and neoadjuvant therapy, women with breast cancer often attempt to seek alternative treatment to improve outcomes. A report in 2002 showed that 63-83\% of breast cancer patients used at least one type of complementary and alternative medicine to prevent the development or progression of breast cancer ${ }^{(3)}$. Nutritional and dietary intake modifications were among the most commonly used complementary and alternative medicines ${ }^{(3)}$. Dietary factors, especially higher vegetable intake, appear to be associated with breast cancer prevention ${ }^{(4,5)}$, although the role of vegetable consumption in breast cancer risk remains controversial $^{(6)}$. Cruciferous vegetables are a subgroup of vegetables of interest to researchers due to their potential cancer-preventive effects ${ }^{(7)}$. A recent metaanalysis including thirteen epidemiological studies showed 
that cruciferous vegetable intake is inversely associated with breast cancer ${ }^{(8)}$.

Cruciferous vegetables are named for their cross-shaped flower petals, and include bok choi, broccoli, Brussels sprouts, cabbage, cauliflower, collard greens, radishes, kale, mustard greens, sauerkraut, turnips and many others. The consumption of cruciferous vegetables is very different across cultures and countries. The average dark green and cruciferous vegetables consumption among US adults aged $25-75$ years was only $0 \cdot 2$ serving daily, according to results from the 1994-1996 Continuing Survey of Food Intakes by Individuals conducted by the US Department of Agriculture $^{(9)}$. This average intake was far less than the intake of cruciferous vegetables of women in Asian countries, who had lower breast cancer incidence (e.g. the estimated median intake was $83 \mathrm{~g} / \mathrm{d}$ among women participating in the Shanghai women's study; $n 73360)^{(10)}$.

The major phytochemicals in cruciferous vegetables are glucosinolates, the precursors of bioactive isothiocyanates (ITC), which appear to modulate breast cancer risk at multiple stages of carcinogenesis through a variety of biological mechanisms. Sulforaphane (SFN) is an ITC derived from cruciferous vegetables and is especially high in broccoli and broccoli sprouts ${ }^{(11,12)}$. A high intake of SFN may reduce breast cancer risk through inducing phase II detoxifying enzymes such as glutathione $S$-transferases, inducing apoptosis and decreasing cell proliferation ${ }^{(11,13)}$. It may also target epigenetic alterations and is an inhibitor of histone deacetylases (HDAC), leading to cell-cycle arrest and apoptosis ${ }^{(14)}$. However, how cruciferous vegetable intake impacts these processes and tumour biomarkers in human breast tissue is unclear. No study has examined cruciferous vegetable and breast tissue biomarkers in vivo.

In the present study, we used the baseline data from a clinical trial of SFN supplementation. The trial was an eight-week, double-blinded, randomized, placebocontrolled study designed to examine effectiveness of supplemental SFN intake in improving biomarkers for cancer prognosis and in altering HDAC activity among women scheduled for breast biopsy. The purpose of the present analysis was to comprehensively examine the relationship between regular cruciferous vegetable intake and selected cancer prognosis-related biomarkers in women's plasma and breast tissue samples before initiation of the SFN supplement intervention.

\section{Methods}

\section{Participants}

Participants were fifty-four women enrolled in a randomized controlled trial conducted at Oregon Health \& Science University's Center for Women's Health Breast Center in Portland, OR, USA from August 2009 to December 2013 (Fig. 1). In brief, women were identified at the time they had suspicious mammographic findings that required breast biopsy at Oregon Health \& Science University, Kaiser
Permanente Northwest and Epic Imaging Clinics, or women from the public sector who found the study listed on clinicaltrials.gov.

English-speaking women were eligible to participate in the study if they were $\geq 21$ years old and had a diagnostic mammogram with results that required biopsy. Exclusion criteria included: invasive breast cancer without DCIS or atypical ductal hyperplasia (ADH), pregnancy, breast-feeding, significant active medical illness, history of or active liver disease or baseline total bilirubin greater than the upper limit of the normal range, allergy to cruciferous vegetables, use of oral antibiotics (except for doxycycline) within three months prior to randomization, oral steroid therapy at enrolment, current therapy with valproate acid or suberoyl + anilide + hydroxamic acid (SAHA), current and planned continuous use of SFN-containing supplements, herbal remedies or pharmaceutical HDAC inhibitors, additional surgeries scheduled within $30 \mathrm{~d}$ of the study start date, neoadjuvant radiation or chemotherapy for currently diagnosed disease prior to or during study supplementation, or any condition possibly exacerbated by participation.

Eligible women met with study coordinators at the Oregon Health \& Science University Clinical and Translational Research Center to review the study's purpose and exclusion criteria. All participants provided informed consent. For the analysis reported in the present paper, only baseline data when participants were first enrolled in the clinical trial were used.

\section{Data collection}

Sociodemographic and lifestyle data were collected through a risk factor questionnaire administered by experienced study coordinators. A spot urine specimen was collected from each participant to rule out pregnancy prior to enrolment and was used to assess concentrations of SFN ITC. Each urine sample was aliquoted into seven small $(1.0 \mathrm{ml})$ vials and labelled. A $30 \mathrm{ml}$ non-fasting whole blood specimen was collected at baseline and processed for analysis of plasma SFN ITC concentrations, HDAC activity and acetylated histones. Paraffin-embedded breast biopsy tissue samples, which were regularly collected and stored as part of the surgical procedure, were requested for our analyses from participants' respective institutional pathology laboratories. All breast biopsy tissues were clinically evaluated for the presence of DCIS and/or ADH or invasive cancer by a board certified pathologist. All biological samples were stored chronologically in a freezer at $-80^{\circ} \mathrm{C}$.

\section{Diet and cruciferous vegetable intake assessment}

Dietary intake was assessed using an intervieweradministered National Cancer Institute (NCI) Diet History Questionnaire (DHQ) and Arizona Cruciferous Vegetable Food Frequency Questionnaire (CVFFQ). The NCI DHQ asked questions regarding the participant's usual dietary intake and the Arizona CVFFQ is a validated assessment 


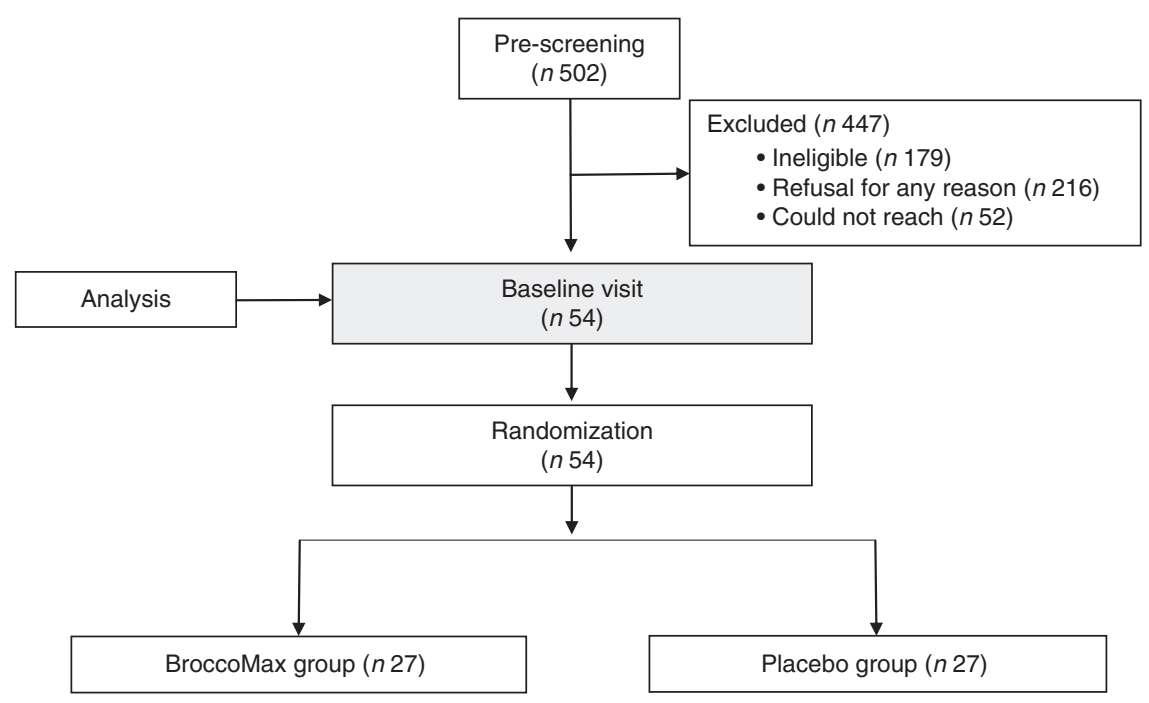

Fig. 1 Sample size flowchart

tool used to specifically quantify cruciferous vegetable consumption $^{(15)}$. This questionnaire lists twenty cruciferous vegetables food lines (each food line asks respondents one specific kind of cruciferous vegetable consumption), six mixed-vegetable dishes and six condiments. It can be used to evaluate cruciferous vegetable intake more accurately than standard $\mathrm{FFQ}^{(15)}$. All questionnaire data were hand-entered into a Clinical and Translational Research Center Bioinformatics-supported REDCap ${ }^{\mathrm{TM}}$ database. Data from the DHQ were analysed using Diet*Calc software. All the items listed on the CVFFQ were linked to the US Department of Agriculture's National Nutrient Database for Standard Reference Release 27 as well as the Food and Nutrient Database for Dietary Studies (FNDDS) version 1.0; each item was given a weighted average based on national consumption data from the National Health and Nutrition Examination Survey. Weight in grams for individual ingredients of mixed dishes and condiments were derived from recipes in FNDDS ${ }^{(16)}$, as was the mean intake in grams of each cruciferous vegetable item listed in the questionnaire.

\section{Measurement of isothiocyanate levels in urine and plasma}

After centrifugation, plasma and urine supernatants were filtered twice through centrifuge tube filters. Plasma filtrates were stored at $-80^{\circ} \mathrm{C}$ until further analysis. Urine filtrates were diluted $1: 2$ with $0 \cdot 1 \%(\mathrm{v} / \mathrm{v})$ formic acid in $\mathrm{H}_{2} \mathrm{O}$ prior to storage. Plasma and urine SFN ITC levels were measured by HPLC-MS/MS at Oregon State University's Mass Spectrometry Core Laboratories using the same materials, methods and instrumentation as previously described ${ }^{(17)}$. Levels were analysed for SFN, SFN-cysteine (SFN-Cys), SFN-glutathione (SFN-GSH), SFN-cysteinylglycine (SFN-CG) and SFN- $N$ acetylcysteine (SFN-NAC) in duplicate following a $10 \mu \mathrm{l}$ injection. Metabolite levels were quantified based on standard curves spanning metabolite concentrations. All urinary SFN ITC levels were adjusted for urine creatinine level.

\section{Measurement of histone deacetylase activity in peripheral blood mononuclear cells}

Analyses were performed by the Cancer Chemoprevention Program's Core Laboratory at the Linus Pauling Institute. Peripheral blood mononuclear cells (PBMC) were isolated using Histopaque (Sigma, St. Louis, MO, USA) separation, suspended in dimethyl sulfoxide and stored in liquid nitrogen until further analysis. PBMC HDAC activity was evaluated using an in-house HDAC substrate Ac-K-Y-K(ac)-AMC. The deacetylated standard was custom synthesized by AAPPTec, LLC (Louisville, KY, USA). The intra-assay CV was $8 \cdot 2 \%$. HDAC activity is expressed relative to protein content in lysate.

\section{Measurement of biomarkers from breast tissues through immunobistochemistry}

Immunohistochemistry was performed on paraffinembedded breast biopsy specimens using methods described by Elsheikh et $a l .{ }^{(18)}$. Slides were prepared from each biopsy core using Fisher Plus slides. These slides were air-dried at $25^{\circ} \mathrm{C}$ then were further dried at $60^{\circ} \mathrm{C}$ in preparation for staining procedures. In order to be appropriately stained with primary antibodies for acetylated histone $\mathrm{H} 3$ at lysine 9 (H3K9) and 18 (H3K18), p21, Ki-67, HDAC6 and HDAC3, slides were deparaffinized in xylenes, rehydrated with graded alcohols, washed in Tris-buffered saline ( $\mathrm{pH} 7 \cdot 2-7 \cdot 6$ ), heated in a Russell-Hobbs programmable pressure cooker in 0.01-м citrate buffer ( $\mathrm{pH}$ 6.0), treated with $3 \%(\mathrm{w} / \mathrm{v})$ aqueous $\mathrm{H}_{2} \mathrm{O}_{2}$ solution, blocked at $25^{\circ} \mathrm{C}$ in $3 \%(\mathrm{w} / \mathrm{v})$ goat serum and then incubated for $1 \mathrm{~h}$ at $25^{\circ} \mathrm{C}$. After incubation with antibodies, the following procedures were performed: mouse EnVision, counterstaining 
with Gill's hematoxylin, rinsing, treating with Tris-buffered saline, dehydration with graded alcohols and xylene, and cover slipping using Permount. Positive and negative control slides were used for technical adequacy of staining. Our collaborating pathologist read the slides and scored both staining intensity (graded as 1-3) and percentage of positive cells. A modified Histo-score (H-score) ranging from 0 to 300 was recorded ${ }^{(19)}$.

\section{Statistical analyses}

Descriptive data on baseline characteristics of all the participants were expressed as means and standard deviations for continuous variables and as counts and percentages for categorical variables. The primary outcomes examined include urine and plasma SFN ITC levels, levels of acetylation at $\mathrm{H} 3 \mathrm{~K} 9$ and H3K18, HDAC activity, Ki-67 and p21. Kolmogorov-Smirnov normality tests were conducted for all continuous variables. HDAC activity in PBMC followed a normal distribution. Tissue biomarkers were not normally distributed and therefore were $\log _{2}$-transformed to obtain approximate normality. Total cruciferous vegetable intake, plasma and urine biomarkers were analysed untransformed.

Our primary interest was to determine whether total cruciferous vegetable intake, combining sources from food, mixed dishes and condiments, is significantly associated with the biomarkers of our primary interest, histone acetylation and cell proliferation. The analysis was conducted separately for each primary end point as well as for each specimen type (e.g. blood, urine, normal tissue, DCIS tissue and invasive ductal carcinoma (IDC) tissue). In order to examine the association between total cruciferous vegetable intake and each biomarker, we first conducted crude and partial Spearman correlation tests, followed by multivariable generalized linear regression analyses adjusting for potential confounders. To account for multiple comparisons, we conducted false discovery rate (FDR) calculation using the Benjamini and Hochberg method ${ }^{(20)}$. All statistical analyses were performed using the statistical software package SAS version 9.4. A FDR $q$ value $<0.05$ was considered statistically significant.

\section{Results}

The baseline characteristics of all participants showed $74 \%$ were white, $37 \%$ had a family history of breast cancer, $26 \%$ were either current or former smokers, $50 \%$ drank alcohol, $22 \%$ had income $\leq \$$ US $25000,11 \%$ had $\leq 12$ years of education, $50 \%$ were married, $52 \%$ were users of nonsteroidal anti-inflammatory drugs, $43 \%$ were postmenopausal women and $48 \%$ were diagnosed with cancer (including DCIS or invasive disease). The mean age was 54.4 (SD 12.1) years among the fifty-four participants (Table 1).
Table 1 Sociodemographic characteristics of women participating in a randomized clinical trial $(n 54)$

\begin{tabular}{|c|c|c|}
\hline Characteristic & Mean & SD \\
\hline Age (years) & $54 \cdot 4$ & $12 \cdot 1$ \\
\hline BMI $\left(\mathrm{kg} / \mathrm{m}^{2}\right)$ & $27 \cdot 3$ & $5 \cdot 6$ \\
\hline Cruciferous vegetable intake $(\mathrm{g} / \mathrm{d})^{\star}$ & $81 \cdot 7$ & $57 \cdot 3$ \\
\hline Total SFN ITC from urine ( $\mu \mathrm{M} ; n$ 43) & 0.08 & 0.07 \\
\hline \multirow[t]{2}{*}{ Total SFN ITC from plasma ( $\mu \mathrm{M} ; n$ 34) } & 0 & 0 \\
\hline & $n$ & $\% \ddagger$ \\
\hline \multicolumn{3}{|l|}{ Race } \\
\hline White & 40 & 74.07 \\
\hline Non-white/missing & 14 & 25.93 \\
\hline \multicolumn{3}{|l|}{ Family history of breast cancer } \\
\hline Yes & 20 & 37.04 \\
\hline No & 34 & 62.96 \\
\hline \multicolumn{3}{|l|}{ Smoking } \\
\hline Current & 2 & 3.70 \\
\hline Former & 12 & $22 \cdot 22$ \\
\hline Never & 32 & 59.26 \\
\hline Missing & 8 & $14 \cdot 81$ \\
\hline \multicolumn{3}{|l|}{ Alcohol } \\
\hline Current & 21 & 38.89 \\
\hline Former & 6 & $11 \cdot 11$ \\
\hline Never & 18 & 33.33 \\
\hline Missing & 9 & $16 \cdot 67$ \\
\hline \multicolumn{3}{|l|}{ Income } \\
\hline$\leq \$$ US 25000 & 12 & $22 \cdot 22$ \\
\hline$\$$ US $25000-50000$ & 4 & $7 \cdot 41$ \\
\hline$>\$$ US 50000 & 25 & $46 \cdot 30$ \\
\hline Refuse/don't know/missing & 13 & 24.07 \\
\hline \multicolumn{3}{|l|}{ Education } \\
\hline$\leq 12$ years & 6 & $11 \cdot 11$ \\
\hline Some college/technical & 11 & 20.37 \\
\hline$\geq$ College graduate & 26 & 48.15 \\
\hline Missing & 11 & 20.37 \\
\hline \multicolumn{3}{|l|}{ Marital status } \\
\hline Single, divorced, widowed & 18 & 33.33 \\
\hline Married/partner & 27 & $50 \cdot 00$ \\
\hline Missing & 9 & $16 \cdot 67$ \\
\hline \multicolumn{3}{|l|}{ Use of NSAID } \\
\hline Yes & 28 & 51.85 \\
\hline No & 25 & $46 \cdot 30$ \\
\hline Missing & 1 & 1.85 \\
\hline \multicolumn{3}{|l|}{ Menopausal status $†$} \\
\hline Pre & 19 & $35 \cdot 19$ \\
\hline Peri & 12 & $22 \cdot 22$ \\
\hline Post & 23 & 42.59 \\
\hline \multicolumn{3}{|l|}{ Pathology biopsy diagnosis } \\
\hline No cancer & 24 & 44.40 \\
\hline Hyperplasia & 4 & $7 \cdot 41$ \\
\hline DCIS or DCIS + ADH & 17 & 31.48 \\
\hline Invasive cancer with DCIS or DCIS + ADH & 9 & $16 \cdot 67$ \\
\hline
\end{tabular}

SFN ITC, sulforaphane isothiocyanates; NSAID, non-steroidal anti-inflammatory drugs; DCIS, ductal carcinoma in situ; ADH, atypical ductal hyperplasia.

${ }^{*}$ Cruciferous vegetable intake includes sources from food lines, mixed dishes and condiments.

†For the thirteen women who did not report their menopausal status, those aged $<45$ years were grouped into premenopausal status, those aged $45-55$ years were grouped into perimenopausal status and those aged $>55$ years were grouped into postmenopausal status.

¥Percentages may not add up to 100 due to rounding.

The mean baseline total cruciferous vegetable intake was 81.7 (sD 57.3) g/d among the total of fifty-four participants. Forty-three of them had data of urinary SFN ITC values and the average total SFN ITC value was 0.08 (SE 0.01) $\mu \mathrm{m} / \mathrm{mm}$ creatinine (Table 2). Crude (unadjusted) and partial (adjusted) Spearman correlation between total cruciferous 
Table 2 Baseline daily intake of selected cruciferous vegetables and urinary sulforaphane metabolites among women participating in a randomized clinical trial

\begin{tabular}{|c|c|c|}
\hline & Mean & SE \\
\hline \multicolumn{3}{|l|}{ Cruciferous vegetables from food lines ( $\mathrm{g} / \mathrm{d} ; n$ 54) } \\
\hline Bok choi & 1.5 & 0.5 \\
\hline Broccoli spears & $13 \cdot 8$ & $2 \cdot 2$ \\
\hline Broccoli florets & $11 \cdot 6$ & 1.8 \\
\hline Brocco flower & $2 \cdot 1$ & 1.0 \\
\hline Broccolini & 3.0 & 1.0 \\
\hline Brussels sprouts & $9 \cdot 2$ & 1.5 \\
\hline Cabbage (green) & 3.3 & 0.8 \\
\hline Cabbage (red) & 1.4 & 0.4 \\
\hline Cauliflower & $15 \cdot 6$ & $2 \cdot 1$ \\
\hline Chinese cabbage/napa & 1.0 & 0.4 \\
\hline Collard greens & $1 \cdot 2$ & 0.3 \\
\hline Daikon root & 0.2 & 0.1 \\
\hline Garden/watercress & $1 \cdot 3$ & 0.7 \\
\hline Kale & 1.5 & 0.6 \\
\hline Kohlrabi & 0.2 & 0.1 \\
\hline Mustard greens & 0.1 & 0.1 \\
\hline Rutabaga & 0.6 & 0.2 \\
\hline Sauerkraut & 0.6 & 0.2 \\
\hline Turnip & 0.9 & 0.2 \\
\hline Turnip greens & $1 \cdot 2$ & 1.0 \\
\hline Total cruciferous vegetables from food lines & $70 \cdot 6$ & 6.9 \\
\hline \multicolumn{3}{|c|}{ Cruciferous vegetables from mixed dishes/juice $(\mathrm{g} / \mathrm{d} ; n$ 54) } \\
\hline Eggroll or spring roll & 0.5 & 0.1 \\
\hline $\begin{array}{l}\text { Vegetable soup or stews with cruciferous } \\
\text { vegetables }\end{array}$ & 3.3 & $1 \cdot 1$ \\
\hline Meat/fish/shellfish with broccoli & $3 \cdot 2$ & 0.6 \\
\hline $\begin{array}{l}\text { Meat/fish/shellfish with other cruciferous } \\
\text { vegetables }\end{array}$ & 0.004 & 0.001 \\
\hline Vegetarian Chinese dishes & $2 \cdot 6$ & 0.6 \\
\hline Stuffed cabbage & $0 \cdot 1$ & 0.04 \\
\hline Juice made with cruciferous vegetables & 0.02 & 0.01 \\
\hline $\begin{array}{l}\text { Total cruciferous vegetables from mixed } \\
\text { dishes/juice }\end{array}$ & $9 \cdot 8$ & 1.5 \\
\hline \multicolumn{3}{|l|}{ Cruciferous vegetables from condiments ( $\mathrm{g} / \mathrm{d} ; n$ 54) } \\
\hline Horseradish & 0.2 & 0.05 \\
\hline Chinese mustard & $0 \cdot 1$ & 0.05 \\
\hline Brown mustard & 0.3 & 0.08 \\
\hline Yellow mustard & 0.3 & 0.1 \\
\hline Mustard seed/powder & 0.07 & 0.02 \\
\hline Wasabi & 0.4 & 0.1 \\
\hline Total cruciferous vegetables from condiments & $1 \cdot 3$ & 0.3 \\
\hline Total cruciferous vegetables from all foods & $81 \cdot 7$ & $7 \cdot 8$ \\
\hline \multicolumn{3}{|c|}{ Urinary sulforaphane metabolites $(\mu \mathrm{M} / \mathrm{mm} \text { creatinine; } n 43)^{*}$} \\
\hline Total SFN ITC & 0.08 & 0.01 \\
\hline SFN-NAC & 0.03 & 0.006 \\
\hline SFN-Cys & 0.03 & 0.004 \\
\hline SFN-GSH & 0.004 & 0.001 \\
\hline SFN-CG & 0.02 & 0.003 \\
\hline SFN & 0.002 & 0.001 \\
\hline
\end{tabular}

SFN ITC, sulforaphane isothiocyanates; SFN-NAC, SFN-N-acetylcysteine; SFN-Cys, SFN-cysteine; SFN-GSH, SFN-glutathione; SFN-CG, SFN-cysteinylglycine; SFN, sulforaphane.

*Urinary metabolite concentrations normalized to creatinine in millimolar concentration.

vegetable intake and biomarkers are shown in Table 3. Partial Spearman correlation showed total cruciferous vegetable intake was significantly correlated with Ki-67 in DCIS $(P=0.009)$ and IDC tissue $(P=0.03)$, and was possibly correlated with p21 in DCIS tissue $(P=0.06)$ after adjusting for age and use of non-steroidal anti-inflammatory drugs. In the multivariable regression analysis adjusting for age and use of non-steroidal anti-inflammatory drugs, total
Table 3 Spearman correlations between total cruciferous vegetable intake and blood as well as tissue biomarkers among women at high risk for breast cancer participating in a randomized clinical trial

\begin{tabular}{|c|c|c|c|c|c|}
\hline \multirow[b]{2}{*}{ Biomarker } & \multirow[b]{2}{*}{$n$} & \multicolumn{4}{|c|}{ Total cruciferous vegetable intake $(\mathrm{g} / \mathrm{d})$} \\
\hline & & $\begin{array}{c}\text { Crude } \\
\text { correlation, } \\
r\end{array}$ & $\begin{array}{l}\text { Crude } \\
\text { correlation, } \\
P \text { value }\end{array}$ & $\begin{array}{c}\text { Partial } \\
\text { correlation, } \\
r\end{array}$ & $\begin{array}{c}\text { Partial } \\
\text { correlation, } \\
P \text { value }^{\star}\end{array}$ \\
\hline $\begin{array}{l}\text { PBMC } \\
\text { HDAC } \\
\text { activity }\end{array}$ & 48 & 0.25 & 0.09 & 0.23 & 0.12 \\
\hline \multicolumn{6}{|l|}{ H3K18ac } \\
\hline Benign & 15 & -0.46 & 0.08 & -0.39 & 0.19 \\
\hline DCIS & 10 & 0.15 & 0.68 & 0.38 & 0.35 \\
\hline \multirow{2}{*}{\multicolumn{6}{|c|}{$\mathrm{H} 3 \mathrm{~K} 9 \mathrm{ac}$}} \\
\hline & & & & & \\
\hline Benign & 32 & 0.28 & 0.12 & 0.26 & $0 \cdot 16$ \\
\hline DCIS & 16 & -0.06 & 0.83 & 0.12 & 0.69 \\
\hline $\begin{array}{c}\text { IDC } \\
\text { HDAC3 }\end{array}$ & 11 & -0.03 & 0.93 & 0.08 & 0.83 \\
\hline Benign & 27 & $-0 \cdot 14$ & 0.50 & $-0 \cdot 13$ & 0.54 \\
\hline DCIS & 7 & 0.66 & 0.11 & -0.43 & 0.47 \\
\hline \multicolumn{5}{|l|}{ HDAC6 } & na \\
\hline Benign & 28 & -0.02 & 0.93 & -0.004 & 0.98 \\
\hline DCIS & 7 & 0.82 & 0.02 & 0.72 & 0.17 \\
\hline IDC & 2 & na & na & na & na \\
\hline \multicolumn{6}{|l|}{$\mathrm{Ki}-67$} \\
\hline Benign & 35 & 0.13 & 0.45 & 0.14 & 0.45 \\
\hline DCIS & 13 & -0.29 & 0.34 & -0.74 & 0.009 \\
\hline \multirow{2}{*}{\multicolumn{6}{|c|}{ p21 }} \\
\hline & & & & & \\
\hline Benign & 37 & -0.18 & 0.28 & -0.19 & 0.27 \\
\hline DCIS & 13 & -0.51 & 0.07 & -0.58 & 0.06 \\
\hline IDC & 9 & 0.31 & 0.42 & 0.35 & 0.44 \\
\hline
\end{tabular}

PBMC, peripheral blood mononuclear cells; HDAC, histone deacetylase; ac, acetylation; DCIS, ductal carcinoma in situ; IDC, invasive ductal carcinoma; na, not available.

Significant results are presented in bold font.

*Partial correlation $P$ value is adjusted for age and use of non-steroidal anti-inflammatory drugs.

cruciferous vegetable intake was significantly inversely associated with Ki-67 in DCIS tissue ( $\beta=-0.004, \mathrm{SE}=0.001$, FDR $q$ value $=0.03$; Table 4 ). Additional adjustment for smoking or alcohol intake did not change the significant association. No association was found for other biomarkers including p21. Because the tissue-derived biomarkers were $\log _{2}$-transformed, $\beta$ coefficients were interpreted as percentages. For Ki-67, a $1 \mathrm{~g} / \mathrm{d}$ increase in cruciferous variable intake was associated with a $0.3 \%$ decrease in Ki-67 level in DCIS tissue. As shown in Fig. 2, the levels of predicted Ki-67 H-score decreased dramatically with increasing total cruciferous vegetable intake, especially after intake of $60 \mathrm{~g} / \mathrm{d}$. In exploratory analyses, the relationship between cruciferous vegetable intake and Ki-67 level appeared to be non-linear with a threshold at an intake of about $60 \mathrm{~g} / \mathrm{d}$. The greatest evidence for an association between cruciferous vegetable intake and Ki-67 level was noted above this threshold. For this reason, we categorized the participants into two groups based on their total cruciferous vegetable intake: (i) $\geq 60 \mathrm{~g} / \mathrm{d}$ (higher cruciferous vegetable intake, $n$ 33); and (ii) $<60 \mathrm{~g} / \mathrm{d}$ (lower cruciferous vegetable 
Table 4 Multivariable regression analysis between total cruciferous vegetable intake and blood as well as tissue biomarkers among women at high risk for breast cancer participating in a randomized clinical trial

\begin{tabular}{|c|c|c|c|c|}
\hline \multirow[b]{2}{*}{ Biomarker } & \multicolumn{4}{|c|}{ Total cruciferous vegetable intake $(\mathrm{g} / \mathrm{d})$} \\
\hline & $\beta$ & SE & $P$ value* & FDR $q$ value \\
\hline PBMC HDAC activity & 1.06 & 0.57 & 0.07 & 0.40 \\
\hline \multicolumn{5}{|l|}{ H3K18ac } \\
\hline Benign & -0.004 & 0.003 & 0.22 & 0.74 \\
\hline DCIS & 0.005 & 0.007 & 0.51 & 0.87 \\
\hline IDC & -0.001 & 0.007 & 0.88 & 0.98 \\
\hline \multicolumn{5}{|l|}{ H3K9ac } \\
\hline Benign & 0.003 & 0.002 & 0.56 & 0.87 \\
\hline DCIS & 0.0004 & 0.004 & 0.92 & 0.98 \\
\hline IDC & 0.002 & 0.004 & 0.65 & 0.88 \\
\hline \multicolumn{5}{|l|}{ HDAC3 } \\
\hline Benign & -0.0005 & 0.002 & 0.80 & 0.97 \\
\hline DCIS & -0.002 & 0.003 & 0.56 & 0.87 \\
\hline IDC & na & na & na & na \\
\hline \multicolumn{5}{|l|}{ HDAC6 } \\
\hline Benign & -0.00007 & 0.002 & 0.98 & 0.98 \\
\hline DCIS & 0.007 & 0.005 & 0.26 & 0.74 \\
\hline IDC & na & na & na & na \\
\hline \multicolumn{5}{|l|}{ Ki-67 } \\
\hline Benign & 0.00009 & 0.0002 & 0.67 & 0.88 \\
\hline DCIS & -0.004 & 0.001 & 0.002 & 0.03 \\
\hline IDC & -0.009 & 0.006 & 0.21 & 0.74 \\
\hline \multicolumn{5}{|l|}{ p21 } \\
\hline Benign & -0.0004 & 0.0005 & 0.45 & 0.87 \\
\hline DCIS & -0.006 & 0.003 & 0.07 & 0.40 \\
\hline IDC & 0.002 & 0.003 & 0.50 & 0.87 \\
\hline
\end{tabular}

FDR, false discovery rate; PBMC, peripheral blood mononuclear cells; HDAC histone deacetylase; ac, acetylation; DCIS, ductal carcinoma in situ; IDC, invasive ductal carcinoma; na, not available; $\mathrm{H}$-score, modified Histo-score. Significant results are presented in bold font.

${ }^{*}$ General linear regression models were used, adjusting for age and use of non-steroidal anti-inflammatory drugs. The units of H3K18ac, H3K9ac, HDAC3, HDAC6, Ki-67 and p21 used in the model were $\log _{2}(\mathrm{H}$-score). †Multiple comparison-adjusted FDR $q$ values for all the breast-tissue immunohistochemistry biomarkers using the Benjamini-Hochberg False Discovery Rate.

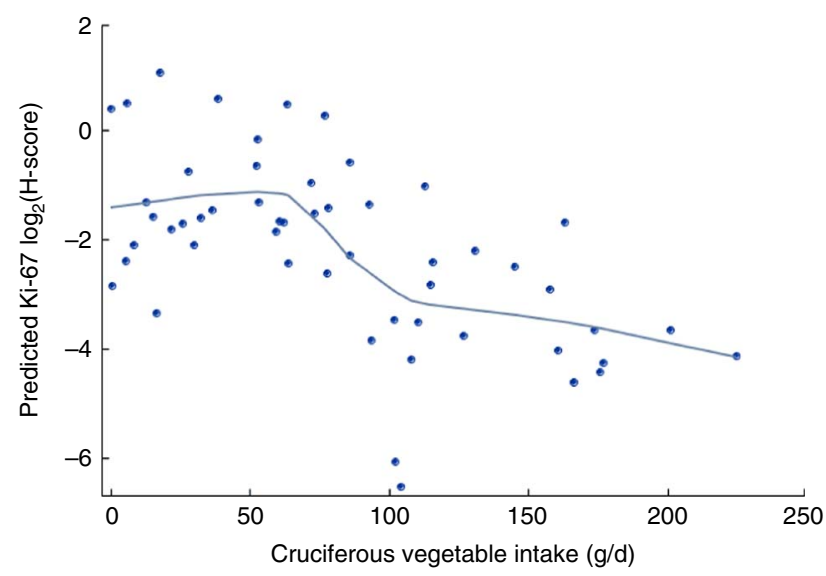

Fig. 2 Ki-67 modified Histo-score (H-score) levels in breast ductal carcinoma in situ tissue and cruciferous vegetable intake among women $(n 54)$ at high risk for breast cancer participating in a randomized clinical trial. Predicted Ki-67 $\log _{2}(\mathrm{H}$-score $)$ levels $(\mathbf{O} ;-$, loess smooth $=0.5)$ are adjusted for age and use of non-steroidal anti-inflammatory drugs. Figure was obtained through SGPLOT procedure in SAS version 9.4 intake, $n$ 21). The association between cruciferous vegetable intake and Ki-67 level was significant among individuals in the higher cruciferous vegetable intake category $(\beta=-0 \cdot 04, \mathrm{sE}=0 \cdot 0, P=0 \cdot 04)$. For those in the lower cruciferous vegetable intake, we did not find a significant association between cruciferous vegetable intake and Ki-67 level $(\beta=-0.04, \mathrm{sE}=0.09, P=0.70)$. However, the magnitude of the association was the same in both groups $(\beta=-0.04)$.

\section{Discussion}

In the current analysis of our fifty-four female participants, we found that total cruciferous vegetable intake was associated with a lower level of Ki-67 in DCIS tissues. We did not observe a statistically significant association between total cruciferous vegetable intake and H3K18ac, H3K9ac, HDAC3, HDAC6 or p21 from the limited sample size.

Although numerous studies have assessed the effects of cruciferous vegetable intake on breast cancer, the relationship between cruciferous vegetable intake and blood or breast tissue biomarkers has received less attention. In a cross-sectional analysis among 1005 middle-aged Chinese women from the Shanghai Women's Health Study, Jiang et al. found that cruciferous vegetable intake was inversely associated with circulating levels of pro-inflammatory markers such as TNF- $\alpha$, IL- $1 \beta$ and IL- $6^{(21)}$. The median intake of cruciferous vegetables was $82.9 \mathrm{~g} / \mathrm{d}$ with an interquartile range of $48.9-138.1 \mathrm{~g} / \mathrm{d}^{(21)}$, which was a little higher than the median intake of cruciferous vegetables in our study population (median $=74.5 \mathrm{~g} / \mathrm{d}$, interquartile range $=32 \cdot 2-114.6 \mathrm{~g} / \mathrm{d}$ ). The most commonly consumed cruciferous vegetables in China included Chinese greens (bok choi), green cabbage, Chinese cabbage (napa), cauliflower and white turnip/radish ${ }^{(21)}$, while the five most commonly consumed cruciferous vegetables in our study population were cauliflower, broccoli spears, broccoli florets, Brussels sprouts and broccolini. Therefore, there was a difference in the food patterns of cruciferous vegetable consumption between these populations. However, no study has examined cruciferous vegetable intake and breast tissue biomarkers in vivo. Our finding of the statistically significant inverse association between total cruciferous vegetable intake and Ki-67 in DCIS tissue is biologically plausible. Ki-67 is a biomarker for cell proliferation. Cell proliferation is a hallmark of cancer, although the level of proliferation differs along cancer disease stages. How breast tissue cells respond to cruciferous vegetable intake and their molecular derivatives at different stages is not well studied. Our report is the first study showing the differential effects of cruciferous vegetable intake, the main source of SFN, on Ki-67 in IDC, DCIS and benign breast tissue. Our observations support the notion that cancer disease stage, including both breast cancer and other types of cancer stage, may influence a cell's response to cruciferous vegetable intake. An in vitro 
study on prostate cells also showed SFN had different effects on cell-cycle arrest and apoptosis in different stages of cells when comparing normal $v$. hyperplastic and cancerous prostate cells ${ }^{(22)}$

Based on our study's exclusion criteria, anyone who took SFN supplements before enrolment was not eligible. Therefore, our analyses of all the baseline (before intervention) plasma SFN ITC levels including total SFN ITC, SFN-NAC, SFN-Cys SFN-GSH and SFN-CG were 0, indicating people were not taking SFN supplements and all the participants enrolled met the non-SFN supplement criterion. Our study did not find a statistically significant correlation between usual cruciferous vegetable intake and urinary SFN ITC as we expected. This finding is understandable given that urinary SFN ITC levels reflect recent intake of SFN, not usual cruciferous vegetable intake, as SFN ITC are eliminated from urine within $48 \mathrm{~h}$ after cruciferous vegetable intake ${ }^{(23)}$. One large study of two cohorts in China, including 3589 women and 1015 men, showed self-reported usual dietary cruciferous vegetable intake was weakly correlated with urinary ITC level $(r=0 \cdot 1149, P<0 \cdot 0001)$, while recent dietary cruciferous vegetable intake was more strongly correlated with urinary ITC level $(r=0.2591, P<0 \cdot 0001)^{(24)}$.

In our analysis of the relationship between total cruciferous vegetable intake and PBMC HDAC activity, we did not observe a significant correlation. This result is outside our expectations, as we hypothesized the cruciferous vegetable intake could decrease HDAC activity. We conducted a sensitivity analysis investigating the relationship between PBMC HDAC and urinary total SFN ITC, and observed a nonsignificant negative relationship $(\beta=-505 \cdot 7, \quad \mathrm{SE}=493 \cdot 6$, $P=0 \cdot 31$ ). The non-significant finding between total cruciferous vegetable intake and PBMC HDAC activity could be due to chance and small sample size.

Genetic factors should be taken into consideration when studying the association of cruciferous vegetable intake and breast cancer risk. Only a few studies have investigated the role of genes in this association. One study using data from the Long Island Breast Cancer Study, a population-based case-control study, reported no interaction between genetic polymorphisms of glutathione $S$-transferases, which are phase II enzymes that metabolize various bioactive compounds, and cruciferous vegetable intake in regard to cancer risk ${ }^{(25)}$. To date, we have not conducted genetic testing on collected blood; therefore, we have not assessed the effects of genetic polymorphisms in our study.

Human gut microbiota is another factor that should be considered when directly evaluating the effect of cruciferous vegetable intake on breast cancer or its related biomarkers. Glucosinolates in cruciferous vegetables can be metabolized to ITC by plant myrosinase or by certain bacteria in the human gut. Previous studies have observed individual differences in glucosinolate metabolism ${ }^{(26-28)}$ and the human gut microbial community could contribute to the individual variation ${ }^{(26,27)}$. To date, only one human study has examined the relationship between cruciferous vegetable intake, ITC production and gut microbiota composition among healthy adults ${ }^{(27)}$. Among these participants who consumed the same amount of cooked broccoli from a standardized meal, the authors found a significant difference in glucosinolate degradation by fecal bacteria between participants with high and low urinary ITC excretion ${ }^{(27)}$. No study has examined the impact of gut microbiota on the effect of cruciferous vegetable intake on cancer biomarkers.

Our study has several strengths. First, we have comprehensive data on biomarkers from urine and blood, and we collected breast biopsy tissue of each participant. We retain the capacity to examine the associations between total cruciferous vegetable intake and biomarkers in the remaining tissue. To our knowledge, our study is the first one examining associations between cruciferous vegetable intake and breast tissue biomarkers in human subjects. Second, cruciferous vegetable intake was assessed specifically by a validated cruciferous vegetable intake questionnaire that has better accuracy in calculating total cruciferous vegetable intake than conventional FFQ. Study limitations include the small sample size of participants and the smaller sample size of available breast tissue specimens. Other limitations include the hospital-based study design, which may limit the generalizability of our results. In addition, the median intake of cruciferous vegetables among participants in our study was higher compared with the general US population. This is within our expectation since our study participants came from a dietary supplement intervention trial, who were more motivated to eat cruciferous vegetables. Therefore, our results may not be generalized to the entire US population.

\section{Conclusion}

Our data suggest that cruciferous vegetable intake is associated with decreased cell proliferation rate indicated by Ki-67 level. From a nutrition perspective, these data reinforce the recommendation of cruciferous vegetable intake in breast cancer prevention. Our results also provide further guidance for individuals to increase their cruciferous vegetable intake, especially among women diagnosed with DCIS, in order to prevent breast cancer cell proliferation. Future population-based studies with larger numbers of participants are needed to increase the generalizability of the study results.

\section{Acknowledgements}

Acknowledgements: The authors are grateful to all the women who took the time to participate in the study (Sulforaphane: A Dietary HDAC Inhibitor and Prevention of DCIS Progression). Sincere appreciation also goes to Dr Megan Troxell for conducting immunohistochemical 
analyses for this study, Dr David Yu for performing HDAC inhibition assays and $\mathrm{Mr}$ Vernon L. Hartz for providing advice on cruciferous vegetable analysis. Financial support: Research reported in this publication was supported by the National Cancer Institute (grant numbers R21 CA132236-01A2 and P01 CA090890); the National Center for Advancing Translational Sciences of the National Institutes of Health (grant number UL1TR000128); and the National Institute of Environmental Health Sciences (grant number P30 ES000210). Clinical Trial Registration: clinicaltrials.gov identifier is NCT00843167. The funders had no role in the design, analysis or writing of this article. Conflict of interest: None. Authorship: Z.Z. conducted statistical analyses, interpreted the data and wrote the first draft of the manuscript; L.L.A. assessed all the biomarkers from urine and blood, and revised the manuscript; J.S., E.H. and P.E.F. conceptualized, designed the study and collected the data; all authors read and revised the draft, and approved the final manuscript. Etbics of buman subject participation: This study was conducted according to the guidelines laid down in the Declaration of Helsinki and all procedures involving participants were approved by the Oregon Health \& Science University and Kaiser Permanente Northwest Institutional Review Boards for the protection of human subjects. Written informed consent was obtained from all participants.

\section{References}

1. Siegel RL, Miller KD \& Jemal A (2015) Cancer statistics, 2015. CA Cancer J Clin 65, 5-29.

2. American Cancer Society (2013) Breast Cancer Facts \& Figures 2013-2014. Atlanta, GA: American Cancer Society, Inc.

3. DiGianni LM, Garber JE \& Winer EP (2002) Complementary and alternative medicine use among women with breast cancer. J Clinl Oncol 20, 18 Suppl., 34S-38S.

4. Rossi RE, Pericleous M, Mandair D et al. (2014) The role of dietary factors in prevention and progression of breast cancer. Anticancer Res 34, 6861-6875.

5. Liu XO, Huang YB, Gao Y et al. (2014) Association between dietary factors and breast cancer risk among Chinese females: systematic review and meta-analysis. Asian Pac J Cancer Prev 15, 1291-1298.

6. Smith-Warner SA, Spiegelman D, Yaun SS et al. (2001) Intake of fruits and vegetables and risk of breast cancer: a pooled analysis of cohort studies. JAMA 285, 769-776.

7. Abdull Razis AF \& Noor NM (2013) Cruciferous vegetables: dietary phytochemicals for cancer prevention. Asian Pac J Cancer Prev 14, 1565-1570.

8. Liu X \& Lv K (2013) Cruciferous vegetables intake is inversely associated with risk of breast cancer: a metaanalysis. Breast 22, 309-313.

9. Johnston CS, Taylor CA \& Hampl JS (2000) More Americans are eating ' 5 a day' but intakes of dark green and cruciferous vegetables remain low. J Nutr 130, 3063-3067.

10. Zhang X, Shu XO, Xiang YB et al. (2011) Cruciferous vegetable consumption is associated with a reduced risk of total and cardiovascular disease mortality. Am J Clin Nutr 94, 240-246.
11. Fahey JW, Zhang Y \& Talalay P (1997) Broccoli sprouts: an exceptionally rich source of inducers of enzymes that protect against chemical carcinogens. Proc Natl Acad Sci U S A 94, 10367-10372.

12. Zhang Y, Talalay P, Cho CG et al. (1992) A major inducer of anticarcinogenic protective enzymes from broccoli: isolation and elucidation of structure. Proc Natl Acad Sci U S A 89, 2399-2403.

13. Gingras D, Gendron M, Boivin D et al. (2004) Induction of medulloblastoma cell apoptosis by sulforaphane, a dietary anticarcinogen from Brassica vegetables. Cancer Lett 203, $35-43$.

14. Pledgie-Tracy A, Sobolewski MD \& Davidson NE (2007) Sulforaphane induces cell type-specific apoptosis in human breast cancer cell lines. Mol Cancer Ther 6, 1013-1021.

15. Thomson CA, Newton TR, Graver EJ et al. (2007) Cruciferous vegetable intake questionnaire improves cruciferous vegetable intake estimates. J Am Diet Assoc 107, 631-643.

16. US Department of Agriculture, Agricultural Research Service (2011) USDA Food and Nutrient Database for Dietary Studies. Beltsville, MD: Agricultural Research Service, Food Surveys Research Group.

17. Clarke JD, Hsu A, Riedl K et al. (2011) Bioavailability and inter-conversion of sulforaphane and erucin in human subjects consuming broccoli sprouts or broccoli supplement in a cross-over study design. Pharmacol Res 64, 456-463.

18. Elsheikh SE, Green AR, Rakha EA et al. (2009) Global histone modifications in breast cancer correlate with tumor phenotypes, prognostic factors, and patient outcome. Cancer Res 69, 3802-3809.

19. McCarty KS Jr, Miller LS, Cox EB et al. (1985) Estrogen receptor analyses. Correlation of biochemical and immunohistochemical methods using monoclonal antireceptor antibodies. Arch Pathol Lab Med 109, 716-721.

20. Benjamini Y \& Hochberg Y (1995) Controlling the false discovery rate: a practical and powerful approach to multiple testing. J R Statist Soc B 57, 289-300.

21. Jiang Y, Wu SH, Shu XO et al. (2014) Cruciferous vegetable intake is inversely correlated with circulating levels of proinflammatory markers in women. J Acad Nutr Diet 114, 700-708.e2.

22. Clarke JD, Hsu A, Yu Z et al. (2011) Differential effects of sulforaphane on histone deacetylases, cell cycle arrest and apoptosis in normal prostate cells versus hyperplastic and cancerous prostate cells. Mol Nutr Food Res 55, 999-1009.

23. Kristensen M, Krogholm KS, Frederiksen H et al. (2007) Urinary excretion of total isothiocyanates from cruciferous vegetables shows high dose-response relationship and may be a useful biomarker for isothiocyanate exposure. Eur J Nutr 46, 377-382.

24. Vogtmann E, Yang G, Li HL et al. (2015) Correlates of selfreported dietary cruciferous vegetable intake and urinary isothiocyanate from two cohorts in China. Public Health Nutr 18, 1237-1244.

25. Steck SE, Gaudet MM, Britton JA et al. (2007) Interactions among GSTM1, GSTT1 and GSTP1 polymorphisms, cruciferous vegetable intake and breast cancer risk. Carcinogenesis 28, 1954-1959.

26. Rouzaud G, Young SA \& Duncan AJ (2004) Hydrolysis of glucosinolates to isothiocyanates after ingestion of raw or microwaved cabbage by human volunteers. Cancer Epidemiol Biomarkers Prev 13, 125-131.

27. Li F, Hullar MA, Beresford SA et al. (2011) Variation of glucoraphanin metabolism in vivo and ex vivo by human gut bacteria. Br J Nutr 106, 408-416.

28. Shapiro TA, Fahey JW, Wade KL et al. (2001) Chemoprotective glucosinolates and isothiocyanates of broccoli sprouts: metabolism and excretion in humans. Cancer Epidemiol Biomarkers Prev 10, 501-508. 